Juliane Ahner

\title{
Investor-Staat-Schiedsverfahren nach Europäischem Unionsrecht
}

Zulässigkeit und Ausgestaltung in Investitionsabkommen der Europäischen Union

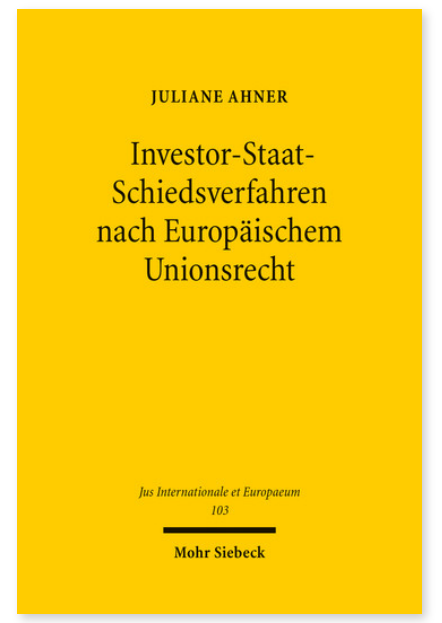

2015. XXIII, 380 Seiten. JusIntEu 103

ISBN 978-3-16-153734-9

DOI 10.1628/978-3-16-153734-9

eBook PDF 104,00€

ISBN 978-3-16-153727-1

fadengeheftete Broschur 104,00€
Juliane Ahner untersucht die Reichweite der Kompetenz der Europäischen Union für ein Investor-Staat-Schiedsverfahren für Auslandsinvestitionen sowie mögliche primärrechtliche Beschränkungen. Dabei kommt sie zu dem Ergebnis, dass die Union gemischte Investitionsabkommen gemeinsam mit den Mitgliedstaaten abschließen muss. Die ausschließliche Zuständigkeit des Europäischen Gerichtshofs für die Auslegung und Anwendung der Verträge und die Autonomie der Unionsrechtsordnung stehen der Unterwerfung unter ein Investor-Staat-Schiedsverfahren nicht entgegen. Juliane Ahner stellt fest, dass die Union nicht alle bestehenden Schiedsverfahren nutzen kann und einige Verfahrensregeln modifiziert werden sollten. Vor dem Hintergrund drohender Schadensersatzansprüche von Investoren gegenüber der Union und den Mitgliedstaaten entwickelt sie Regelungen für die völkerrechtliche und die unionsinterne Haftung.

Juliane Ahner Geboren 1984; Studium der Rechtswissenschaften an der Bucerius Law School, Hamburg, und der Osgoode Hall Law School, Toronto, mit dem Schwerpunkt Europäisches und Internationales Recht; Wissenschaftliche Mitarbeiterin in einer Wirtschaftskanzlei; Referendariat am Kammergericht Berlin und in Sarajewo; 2014 Promotion.
Jetzt bestellen:

https://mohrsiebeck.com/buch/investor-staat-schiedsverfahren-nach-europaeischem-unionsrecht-9783161537349? no_cache=1

order@mohrsiebeck.com

Telefon: +49 (0)7071-923-17

Telefax: +49 (0)7071-51104 